\title{
Billboards And Petrocultures in West TeXas
}

\author{
GiOVANNi Frigo
}

\section{Introduction}

Driving West on Interstate 20 (I-20) from Dallas toward the "art mecca" of Marfa is a remarkable petrocultural experience. The vast landscape made of grasslands, mesquite shrubs, anonymous suburbs, and dispersed cattle ranches slowly gives way to semi-desert open prairies. At some point, the fringes of the road become increasingly filled with oil and gas equipment (rigs, separators, tanks, and containment silos) as well as actual drilling operations (pump jacks, fracking wells). Although petroleum was first discovered in the Permian Basin at the turn of the twentieth century, over the past two decades the area has been reborn due to the so-called "shale revolution." But this new boom in oil and gas extraction does not signify only the successes of hydraulic fracturing and horizontal drilling. It also represents the renewal of the old alliance between the long-established technoscientific endeavour of drilling and the deeply rooted petroculture of West Texas.

This article proposes to investigate the philosophy behind the shale revolution by discussing how the petroculture ${ }^{1}$ of the Permian Basin is expressed on the surface of specific media: billboards. During a trip aimed at studying Indigenous-led protests against the construction of the Trans Pecos Pipeline (TPPL), I drove through the "boomtowns" of the basin, one after another-Midland, Odessa, and Pecos. In doing so, I observed that the roadsides of I-20 are swarming with a rich variety of advertisements: drilling

\footnotetext{
${ }^{1}$ Stephanie LeMenager, Living Oil: Petroleum Culture in the American Century (Oxford: Oxford University Press, 2014); Sheena Wilson, Adam Carlson, and Imre Szeman, "Introduction: On Petrocultures: Or, Why We Need to Understand Oil to Understand Everything Else," in Petrocultures: Oil, Politics, Culture, eds. Sheena Wilson, Adam Carlson, and Imre Szeman (Montreal \& Kingston: McGill-Queen's University Press, 2017), 3-20; Imre Szeman, On Petrocultures: Globalization, Culture, and Energy (Morgantown, WV: West Virginia University Press, 2019).
} 
equipment, cranes, safety courses, Christian faith advocacy, steakhouses, bars, and striptease clubs. Besides the rather uniform advertisements of famous American chains, I noticed that other and more "local" billboards tend to promote various goods or services through a series of common themes. My thesis is that billboards related to oil and gas extraction constitute nuanced forms of "petromedia" whose semantics and design reinforce a specific "philosophy of energy." In other terms, this amounts to a cultural narrative made of images and slogans which portray the "petroaesthetics"3 of West Texas (although it is not unique to this region).

Overall, the petrocultural philosophy of the Permian Basin appears strongly anthropocentric. It promotes ideas such as the instrumentality of nature, domination over untamed land, technoscientific power, drilling prowess, rugged individualism, masculinity, and other foundational values and sociocultural imaginaries of West Texas. By attracting drivers' attention, this pervasive narrative appeals to their imagination with subtlety and creativity. Although they are often dismissed or simply taken for granted, I suggest that billboards contribute to Texas oil industry's ideological construction, ${ }^{4}$ reinforcing a sort of fossil-fuels propaganda. In this way, the long-standing petroculture of the Permian Basin is further cemented and normalized through aesthetic means. To some extent, it also protrudes to influence non-fossil advertisements such as restaurants and bars. Driving through this petrolandscape stimulates a reflection about the "crude reality" of our addiction to fossil fuels. ${ }^{5}$ It allows us to ponder on the links between energy transition, petroculture, advertising, deception, and climate change.

The idea of researching how visual media are used to promote fossil fuels is not new. Some authors have already investigated the relationship between the notion of "media" and energy. ${ }^{6}$ Several authors have researched

\footnotetext{
${ }^{2}$ Giovanni Frigo, "Toward an Ecocentric Philosophy of Energy in a Time of Transition," (PhD dissertation, University of North Texas, 2018).

${ }^{3}$ Catherine Zuromskis, "Petroaesthetics and Landscape Photography," in Oil Culture, eds. Ross Barrett and Daniel Worden (Minneapolis, MN: University of Minnesota Press, 2012), 289-308.

${ }^{4}$ Daniel Worden, "Texas," in Fueling Culture 101: Words for Energy and Environment, eds. Imre Szeman, Jennifer Wenzel, and Patricia Yaeger (New York: Fordham University Press, 2017), 349-352.

${ }^{5}$ Brian Black, Crude Reality: Petroleum and World History (Lanham, MD: Rowman and Littlefield, 2012).

${ }^{6}$ Lisa Gitelman, "Media," in Fueling Culture 101: Words for Energy and Environment, eds. Imre Szeman, Jennifer Wenzel, and Patricia Yaeger (New York: Fordham University Press, 2017), 215-216.
} 
how fossils fuels are portrayed and communicated through films ${ }^{7}$ and different visual media including advertisements. ${ }^{8}$ Drawing from the theme of this collection-"oil and media, oil as media"-as well as from the writing style of Jean Baudrillard's America (1988), this article blends theoretical analysis of billboards with travel writing. It contributes to the field of energy humanities ${ }^{9}$ through a reflection on the specificity of billboards as petromedia in one of the most important locations for oil and gas extraction worldwide, as illustrated by Daniel Worden's entry on "Texas" in Fueling Culture.

After briefly describing the main features of the shale revolution, in part two I reflect on the experience of driving through what has been affectionately called "oil country." Part three grapples with the specificity of billboards, posters, and highway signs as petromedia, considering their materiality, history, semiotics, semantics, and symbolism. Finally, in part four I present photographic evidence and commentary ${ }^{10}$ to highlight the specificity of the petroculture expressed on the billboards. We will see that the outdoor marketing of the Permian Basin not only illustrates the pervasiveness and ubiquity of fossil fuel extraction in the region, but also communicates surprising stories about ghost cities, social struggles, Indigenous struggles, and complex policymaking.

\footnotetext{
7 Worden, 349-352.

${ }^{8}$ Catherine Cudis, Buyways: Billboards, Automobiles, and the American Landscape (London: Routledge, 2004); Peter Hitchcock, "Oil in an American Imaginary," New Formations 69, no. 1 (2010): 81-97; Sheena Wilson, “Gendering Oil: Tracing Western Petrosexual Relations," in Oil Culture, eds. Ross Barrett and Daniel Worden (Minneapolis, MN: University of Minnesota Press, 2014), 244-264; Ross Barrett, "Picturing a Crude Past: Primitivism, Public Art, and Corporate Oil Promotion in the United States," Journal of American Studies 46, no. 2 (2012): 395-422; Matthew T. Huber, Lifeblood: Oil, Freedom, and the Forces of Capital (Minneapolis, MN: University of Minnesota Press, 2013); Hugh D. A. Goldring and Nicole Burton, The Beast: Making a Living on a Dying Planet, ed. Patrick McCurdy (Grand Forks, ND: Digital Press at the University of North Dakota, 2018).

${ }^{9}$ Dominic Boyer and Imre Szeman, "Breaking the Impasse: The Rise of Energy Humanities," University Affairs, February 12, 2014, https://www.universityaffairs.ca/opinion/in-myopinion/the-rise-of-energy-humanities/; Jeff Diamanti and Brent Ryan Bellamy, "Editors' Introduction: Envisioning the Energy Humanities," Reviews in Cultural Theory 6, no. 3 (2016): 1-4; Szeman, "On the Energy Humanities; or, What Can Philosophy Tell Us About Oil?" European Union Centre of Excellence Working Papers 1 (2015): 1-22; Szeman, Imre, and Dominic Boyer, eds. Energy Humanities: An Anthology (Baltimore, MD: Johns Hopkins University Press, 2017).

${ }^{10}$ I propose to use a commentary of the advertisements' photographs as an experimental method to critically analyze and criticize their visual and conceptual features.
} 


\section{Shale Cowboys: Setting the Stage for the Shale Revolution}

A good way to begin grasping the relevance of the fracking boom is with the documentary Shale Cowboys: Fracking Under Trump by Dutch director Nordin Lasfar as it digs deeply into the Texas petroculture and captures its values and priorities. The documentary begins with an aerial shot of different energy infrastructure and the following commentary that frames Texan oil men as the alleged heroes behind the drilling revolution:

In recent years a silent revolution has taken place. We thought the age of fossil fuels was coming to an end and we hoped we were heading for a future filled with renewable energy. But in Texas, deep in the heart of the old oil industry, a handful of men have caused a dramatic shift, putting the United States firmly back on the map as an oil and gas producing superpower. ${ }^{11}$

This excerpt contains two main messages. First, the shale revolution depends on the efforts of few entrepreneurial men whose ingenuity is challenging the pace of the global energy transition. Second, the fracking boom has been influencing the language of US energy policy and politics. In fact, the traditional rhetoric used since the energy crises of the 1970s (and maintained at the start of the shale revolution under the Obama administration) was made up of expressions such as energy "autonomy" and "security." However, in the Trump era, there has been a semantic shift toward more ambitious (and aggressive) messages. For America to become "great again," it needs to become the energy superpower. Accordingly, new labels have been coined, such as "energy independence" or "energy world dominance" which mirror the famous branding of the current US energy policy: "America First!" But let us briefly consider how we got to the shale revolution in the first place.

Although shale gas was first extracted in Fredonia, New York in 1821, and experimental horizontal drilling was attempted as early as the 1930s, it was only in 1947 that the first well was "fracked" in the Hugoton gas field in Grant County, Kansas. ${ }^{12}$ In his 2017 article "The Dark Bounty of Texas Oil," Lawrence Wright explains that

by the mid-nineties, the oil business in the U.S. was lagging. The industry seemed to be on the verge of Peak Oil - the moment when at least half of all the recoverable oil in the world

\footnotetext{
${ }^{11}$ Shale Cowboys: Fracking under Trump, directed by Nordin Lasfar (2017; Netherlands: VPRO), https://www.youtube.com/watch?v=-IzgyM1r1y8.

12 D.R. Suchy and K.D. Newell, "Hydraulic Fracturing of Oil and Gas Wells in Kansas," Kansas Geological Survey Public Information Circular 32 (May 2012): 1.
} 
has been exploited. On the other side of that peak lay an unyielding slope of diminishing returns. The major oil companies began concentrating their exploration efforts outside the U.S., whose reserves were deemed to be more or less used up. The end of the fossil-fuel era was not exactly imminent, but it was no longer unimaginable. ${ }^{13}$

Challenging the notion of peak oil, the pioneering spirit of contractorswildcatters such as George P. Mitchell, the former head of Houston-based Mitchell Energy, led to the invention of new techniques to exploit previously unworkable reservoirs. Shale deposits such as the "Marcellus" in Pennsylvania, the "Barnett" in North Texas, or the "Niobrara" in northeastern Nebraska became famous as the geological scenes of these groundbreaking discoveries (Figure 1). Shale reservoirs are made of a type of finegrained sedimentary rock with low permeability, typically found at greater depths than traditional "bubblelike" deposits. The shale is porous and potentially contains vast amounts of

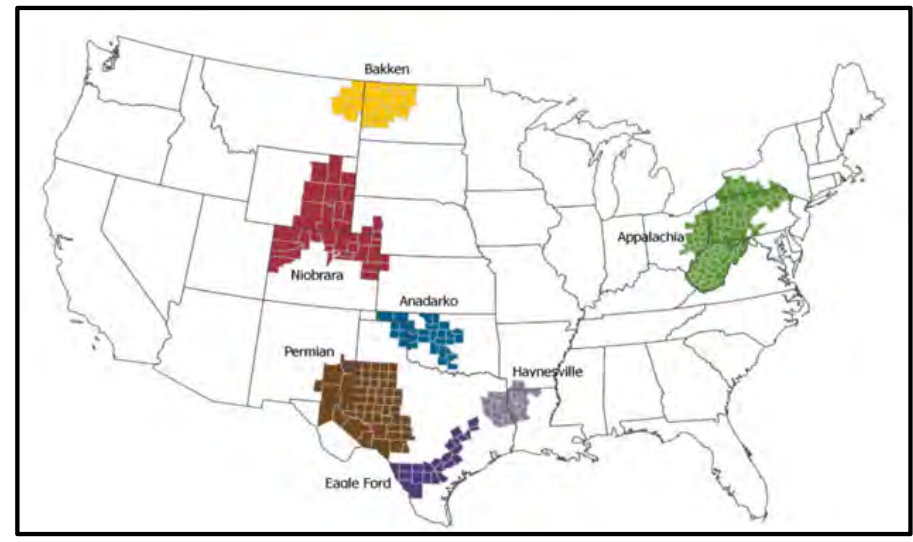

Figure 1: Shale deposits in the USA. Source: EIA Drilling Report March 2018 slowly absorbed fossil

fuels. The technique of shale fracking consists of a combination of horizontal drilling and hydraulic fracturing - the injections at high pressures of a mixture of water, sands, and specific chemicals (whose primary function is to increase the viscosity of the water to carry the grains of sand more efficiently). The amalgam of chemicals can even be copyrighted, hence the notorious "secret recipe" that has alarmed the public. ${ }^{14}$ The fracking process "stimulates" the shale rock creating fractures, thus increasing permeability: oil and gas are released into the well. Due to the pressure differential, gaseous materials flow backwards up the pipe through the wellbore and reach the surface rig where,

${ }^{13}$ Lawrence Wright, "The Dark Bounty of Texas Oil," The New Yorker, December 25, 2017, https://www.newyorker.com/magazine/2018/01/01/the-dark-bounty-of-texas-oil.

${ }^{14}$ See, for example, Hilary S. Boudet et al., "The Effect of Geographic Proximity to Unconventional Oil and Gas Development on Public Support for Hydraulic Fracturing," Risk Analysis 38, no. 9 (2018): 1871-90. 
once the well is active, a production unit is placed in the form of either a set of valves known as the "Christmas tree" or a more traditional "pump jack." Then, the extracted materials are heated in tanks and separated into heavier or lighter hydrocarbons and water. Heavier oils are directed to a refinery (Picture 1 shows that of Big Spring, TX) while the gases go to processing plants, where they will be further separated into butane, propane, and methane.

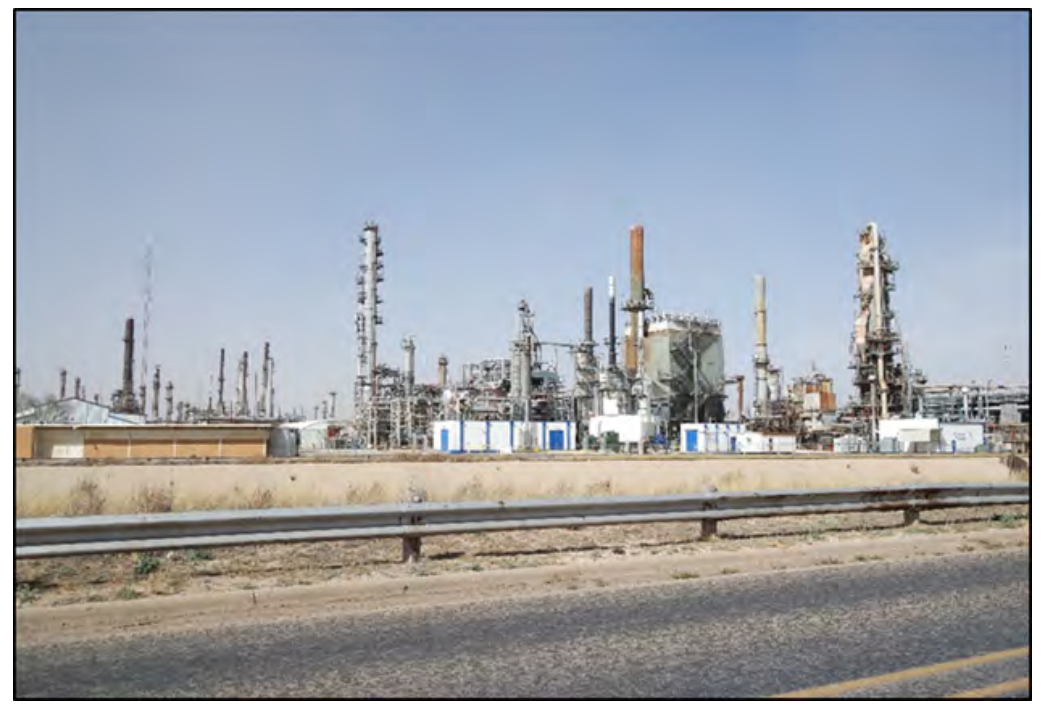

Picture 1: The enormous Big Spring Refinery along I-20, Big Spring

But Shale Cowboys does much more than just describe the revolution that took off in North Texas in the late 1990s. It allows the viewer to peek into the mentality that oozes from the characters interviewed. For example, it draws heavily on Mitchell's prowess and stubborn personality. The peculiar context of Texan petroculture is made of an unquestioned enthusiasm for petroleum, disdain for excessive regulations, and devotion to a type of entrepreneurial life that links neoliberalism to peculiar modes of oil production and consumption. ${ }^{15}$ Mitchell's company has been operating since the 1990s in the Barnett Shale, a newly discovered deposit rich in oil and gas that extends west of the cities of Fort Worth and Denton. ${ }^{16}$ Despite not being able to obtain profits for several years, Mitchell Energy persevered with explorations and experimental drilling of shale deposits.

\footnotetext{
${ }^{15}$ Matthew T. Huber, "Refined Politics: Petroleum Products, Neoliberalism, and the Ecology of Entrepreneurial Life," Journal of American Studies 46, no. 2 (May 2012): 301.

${ }^{16}$ M.K Fisher et al., "Optimizing Horizontal Completion Techniques in the Barnett Shale Using Microseismic Fracture Mapping," SPE Annual Technical Conference and Exhibition 90051 (2004): 1.
} 
Wright recalls that, in the mid-twentieth century, prospectors tried all kinds of means to extract oil and gas from shale: dynamite, machine guns, bazookas, napalm, even nuclear explosions (e.g. Project Plowshare). In the words of the protagonists interviewed by Lasfar, the shale revolution depends on breakthroughs in shale oil and gas exploration and recovery that were firstly developed near Newark, Texas, a small city northwest of Fort Worth. The real breakthrough came in 1997 when Mitchell's engineer Nick Steinsberger applied the slick water fracturing technique, using more proportions of water and higher pump pressure compared to previous attempts. Consequently, in 1998, Mitchell Energy was the first company capable of achieving economically viable extraction in the Barnett deposit through the CW Slay No. 1 discovery well (originally fracked seventeen years earlier, in 1981, but never profitable until that point). This event opened the doors to the boom of perforations, stimulations, and harvesting that makes up today, in North Texas alone, more than 16,000 producing wells owned by about 180 operators (but only about ten top major ones). Since the success of CW Slay No. 1, a series of other techno-scientific innovations and a stubborn craving for profit have refined the fracking process to reach unprecedented productivity, efficiency, economic feasibility and gains.

To better understand the size of this phenomenon, we can turn to a rather tendentious, old, but still informative 2004 article that appeared in the Oil \& Gas Journal. It points out that in 1994 (four years before CW Slay No. 1 achieved feasibility) there were 121 wells in the area of Newark, with Mitchell operating 110 of them. By 2002, there were about 1,120 wells operated by 33 companies, an increase of $926 \% .{ }^{17}$ On August 11, 2011 the Texas Railroad Commission recorded a total of 15,269 gas wells and 3,152 permitted locations. ${ }^{18}$ Discussing the dominant role played by the state of Texas, Wright informs that, mostly because of high oil prices,

a disproportionate share of America's economic growth over the past decade has come from Texas. The gross domestic product of the state is $\$ 1.6$ trillion; if it were an independent country, its economy would settle in around tenth place, eclipsing those of

\footnotetext{
${ }^{17}$ N. M. Rach, "What a Typical Small Operator Experience in the Barnett Shale Play," Oil \& Gas Journal 102, no. 3 (2004): 48. Moreover, Professor Paul Stevens reports that "shale gas rose from less than $1 \%$ of domestic gas production in the United States in 2000 to over $20 \%$ by 2010 . The Energy Information Administration projects that it will account for $46 \%$ of United States gas supply by 2035." See Paul Stevens, "The 'Shale Gas Revolution': Developments and Changes," Chatham House Briefing Paper 4 (August 2012): 2.

${ }^{18}$ See: https://www.rrc.state.tx.us/data/fielddata/barnettshale.pdf
} 
Canada and Australia. California, with forty per cent more residents, has a G.D.P. of $\$ 2.6$ trillion, but since 2000 job growth in both Dallas and Houston has expanded by about thirty per cent - three times the rate of Los Angeles. ${ }^{19}$

The effects of this unexpected oil and gas bounty have been dramatic, changing the United States' energy balance, policy, political affairs, and, with them, key geopolitical equilibria. ${ }^{20}$ After decades of dependence on foreign imports (which still continues), the US has become a leading energy exporter and it is currently the first fossil fuels producer worldwide (first in both oil and gas, third in coal). By considering these facts it is hard to deny that the shale revolution is one of the most groundbreaking events of the new century. The pioneering spirit that fuels it is also an integral part of the landscape of the Permian Basin (Picture 2).

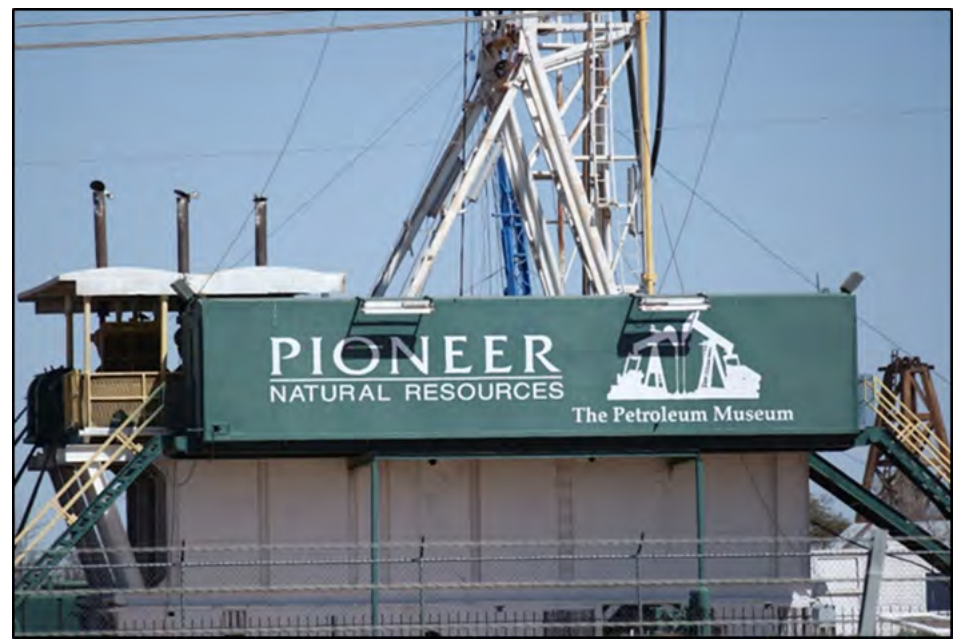

Picture 2: Pioneer Company shares a billboard with the Petroleum Museum in Midland, TX

Unsurprisingly, the techniques to recover oil and gas from shale deposits have been exported from Texas to several other areas of the United States and abroad, leading to a worldwide boost in oil and gas production along

\footnotetext{
${ }^{19}$ Wright, "The Dark Bounty of Texas Oil."

${ }^{20}$ Kentaka Aruga, "The U.S. Shale Gas Revolution and Its Effect on International Gas Markets," Journal of Unconventional Oil and Gas Resources 14 (2016): 1-5; Jasmin Cooper, et al., "Shale Gas: A Review of the Economic, Environmental, and Social Sustainability," Energy Technology 4, no. 7 (2016): 772-92; Leonardo Maugeri, "Oil: The Next Revolution," Discussion Paper 2012-10 (Cambridge, MA: Belfer Center for Science and International Affairs, Harvard Kennedy School, June 2012); and Sergey S. Zhiltsov, Shale Gas: Ecology, Politics, Economy (Cham, CH: Springer, 2017).
} 
with widespread protests and diffused socio-political turmoil. In Texas, for instance, controversies occurred in the city of Denton and around the area of Alpine-Marfa. In the first case, a grassroots movement- "Frack Free Denton" 21 _ achieved the call for a referendum that led to the temporary ban of fracking operations within the city limits. However, Dentonites enjoyed a short-lived victory because, immediately after the ban, the State of Texas promulgated (probably under the pressure of oil and gas lobbyists) House Bill 40 , effectively preventing municipal control over oil and gas extraction. ${ }^{22}$ The second case concerns the Pecos region of southwestern Texas, where local protests contested several controversial aspects surrounding the construction of the Trans-Pecos Pipeline (TPPL), including the lack of consultation with Indigenous communities, as well as health and environmental concerns. What follows is the story of my encounter with this interesting linguistic landscape.

\section{Driving Through Oil Country}

The Permian Basin spans from western Texas to southeastern New Mexico (Figure 2). It extends beneath an area of approximately 250 miles (400 km)

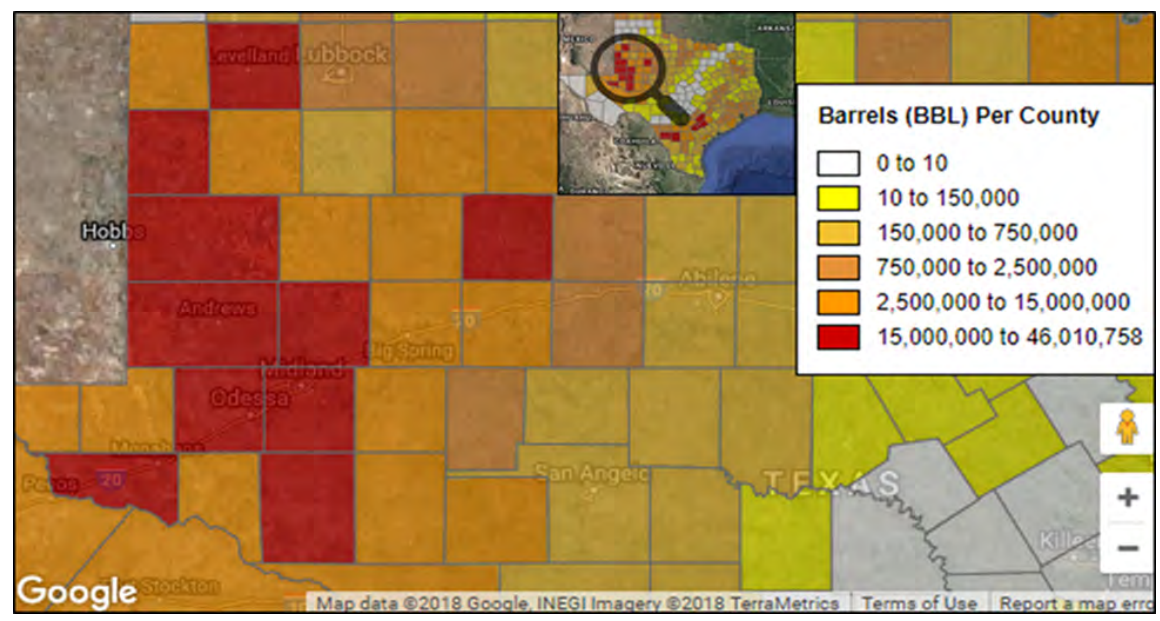

Figure 2: Map of oil productivity in West Texas. Unit of volume for crude oil and petroleum products. One barrel equals 42 US gallons or 35 UK (imperial) gallons, or approximately 159 liters. Notice, in "red," Howard (Big Spring), Midland (homonym city), etc.

${ }^{21}$ See "Frack Free Denton | A project of the Denton Drilling Group," Frack Free Denton, http://frackfreedenton.org/.

${ }^{22}$ Adam Briggle, A Field Philosopher Guide to Fracking: How One Texas Town Stood Up to Big Oil and Gas (New York: Liverlight Publishing Corporation, 2015); Matthew Fry et al., "Fracking and Environmental (In)Justice in a Texas City," Ecological Economics 117 (2015): $97-107$. 
wide and 300 miles $(480 \mathrm{~km})$ long. The portion located in the state of Texas is situated approximately between the counties of Lubbock (North), Pecos (South), Reeves (West), and Nolan (East). Historically, there is evidence of human presence in the region since at least 12,000 years ago (Clovis and Folsom Paleoindians), as evidenced by the skeletal remains of the human labeled "Midland Minnie," discovered in 1953. For millennia, the Permian Basin and the Pecos region more generally have been inhabited by mostly nomadic Indigenous peoples which pushed each other into different territories over time. The most significant Native American populations to inhabit the region were the Jumano, eastern Pueblos, Comanche, and Apache tribes. As the original term Tejas reminds us, this and other regions of Texas were inhabited long before the arrival of the Spaniards. Today, most of the population is made up of descendants of this complex history of migrations and influences among native American, Mexican, and European peoples. The region has been the site of historic ranching operations before the discovery of oil and there are many long-standing communities with peculiar traits. Especially since the 1920s, the oil boom attracted more people to the region. As an explanatory label at the Petroleum Museum located at the entrance of the city of Midland recites, "at 7:45 pm on July 20th, 1920, a vast plume of oil erupted from the 2,754 feet deep well. The Permian Basin oil story had begun." That, along with the establishment of training bases during World War II, led to a further "urban explosion" of early 1900s "boomtowns" such as Midland and Odessa, or what is quickly becoming "Midessa."

But despite a long tradition of conventional vertical drilling, the groundbreaking novelty of the past two decades is that enormous shale deposits have been found underneath the conventional reservoirs of crude, thus renewing interest in the Pecos region and, with that, a prideful "resurgence of American individualism and frontier spirit." 23 Indeed, the Permian Basin has been recognized as one of the most important oil and gas deposits worldwide where major enterprises with telling names thrive (Pioneer Natural Resources, Chevron, ExxonMobil, Apache, Occidental, and Concho Resources). ${ }^{24}$ The Permian Basin is composed of the Wolfcamp, Leonard, Avalon, and Bone Spring formations that contain multiple stacked reservoirs. Together they produce the impressive amount of more than 2.4 million barrels $(\mathrm{Bbl})$ of oil and more than 9,500 millions of cubic feet (MMcf) of gas per day. Given these

\footnotetext{
${ }^{23}$ Frederick Buell, "A Short History of Oil Cultures: Or, the Marriage of Catastrophe and Exuberance," Journal of American Studies 46, no. 2 (2012): 283.

${ }^{24} \mathrm{See}$, for instance, EIA, "Permian region natural gas prices fall as production continues to grow," EIA.gov, July 18, 2018, https:/www.eia.gov/todayinenergy/detail.php?id=36673.
} 
premises one can immediately understand why the shale revolution outlined above has enormously affected West Texas, hence the entire USA.

Furthermore, one may find it surprising that, in addition to the shale revolution, the presence of high velocity winds makes West Texas one of the most important locations for wind energy nationwide. Along I-20, the driver may look at the landscape with puzzling curiosity: the repetitive swinging of pump jacks, the hi-tech looks of fracking wells equipped with solar panels, and in the background extended industrial windfarms (Picture 3). This vast energy infrastructure is impressive and suggests that renewable energy developments overlap longstanding "carbonscapes" 25 in a peculiar sort of energy transition.

Along the Interstate, abandoned oil equipment is beaten by incessant dusty winds and slowly consumed under the burning sun. Despite the general

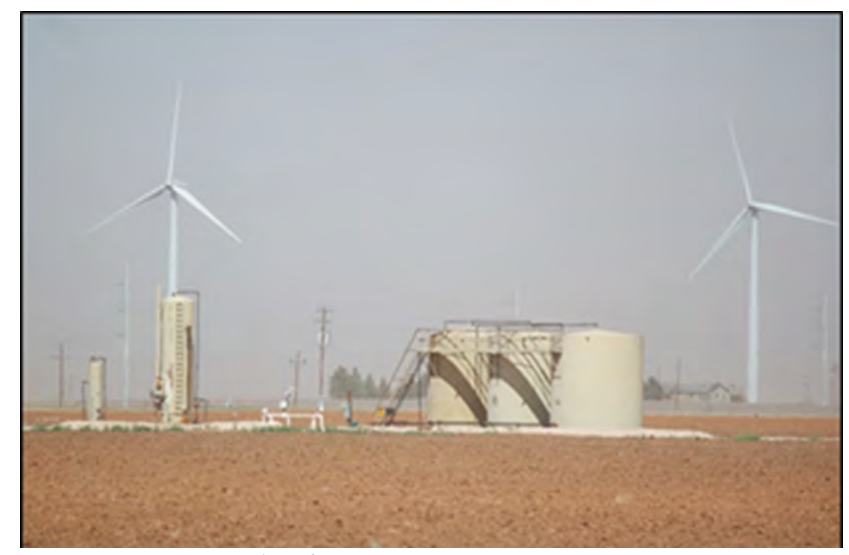

Picture 3: Example of energy transition, or integration in West Texas desolation, the "Now

Hiring" signs are common between Midland and Odessa, suggesting again that the economy is expanding and, with it, the use of alcohol and drugs by the workers who have to bear long shifts in the oil fields. ${ }^{26}$ Around the streets of Midland and Odessa, references to the size of Texas abound, such as in the case of "BigTex Trailers" or the enormous "Million Barrel Tank" built by Shell Oil in the late 1920s but never functional (today all that remains is a run-down museum). The essential but robust infrastructure of the highway tells a story of pragmatic functionality. All around, large pickup trucks covered in dust dominate the road from dawn until late at night. It is clear that the current oil and gas extraction is tied to a glorious past. An aura of nostalgia surrounds advertising boards such as "O-TEX Pumping" (where the ' $O$ ' stands in for "Ole" or "Old," see Picture 4). The sides of the road are swarmed with poorly

\footnotetext{
${ }^{25}$ Håvard Haarstad and Tarje I. Wanvik, "Carbonscapes and Beyond: Conceptualizing the Instability of Oil Landscapes," Progress in Human Geography 41, no. 4 (2017): 433.

${ }^{26}$ Tsvetana Paraskova, "Coke, Meth and Booze: The Flip Side of the Permian Oil Boom," OilPrice.com, July 29, 2018, https://oilprice.com/Energy/Crude-Oil/Coke-Meth-And-BoozeThe-Flip-Side-Of-The-Permian-Oil-Boom.html.
} 


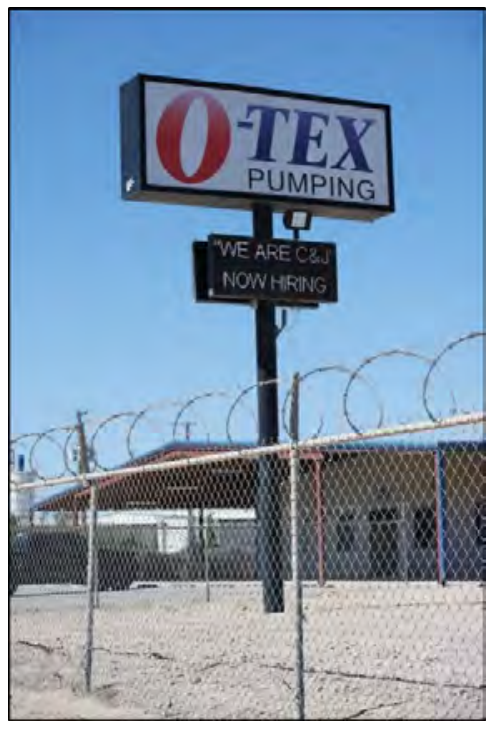

Picture 4: A hint of nostalgia for the "good ole days" in the billboard of $O$ TEX Pumping, LLC in Midland, TX

maintained households and trailers, many of which are unusable or just crumbling. The fences beside the roadway are made of simple barbwire, trapping countless plastic bags that wave irregularly as the wind blows. Road signals and the general highway infrastructure are functional, but worn out and unadorned. It is also evident that there is scarce attention to details such as street furniture compared to other areas of Texas.

No matter how gloomy the atmosphere may sometimes appear, there is something attractive in this extreme desolation, a tragic feeling of hope and pride probably derived from the fossil-fuels boom, a sensation that is difficult to describe (Picture 5).

Despite the risk of "petromyopia"27 - the correct consideration that oil is currently over-represented in the energy humanities - it is still important to

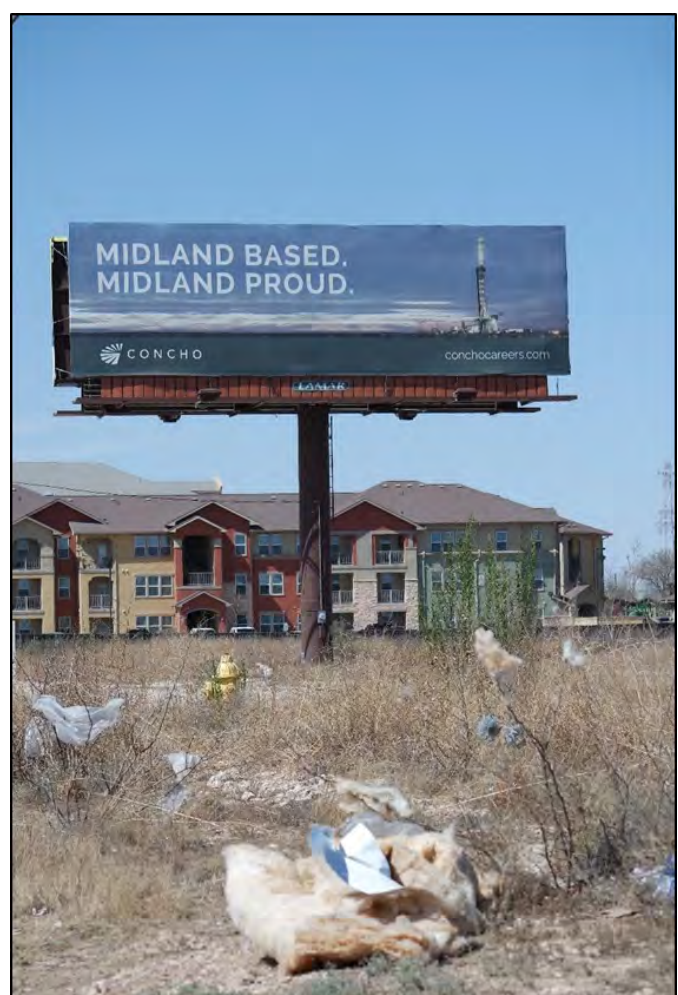

Picture 5: Midland-based Concho Resources, Inc. clarifies that it is a "local" business underscore that petroleum is more than a product or commodity. On the one hand, it has been fueling the realization of projects such as the interstate or railroad systems. On the other hand, it has been the basis for the concrete actualization of Western cultural

${ }^{27}$ Christopher Jones, "Petromyopia: Oil and the Energy Humanities," Humanities 5, no. 2 (2016): 36 . 
ideals such as Manifest Destiny and the Frontier Spirit. ${ }^{28}$ In this regard, Peter Hitchcock explores the subtleties of Americans' encounter with and addiction to oil. He highlights the geopolitical intricacies (think about the wars in the Gulf and Iraq, or the tensions around the Strait of Hormuz) as well as the contradictions of oil (exploitation of the Global South and of cheap labor for the benefits of some), both of which have a special place in the American imagination. These entanglements are not only retrievable in literary classics such as Upton Sinclair's Oil! but are also characteristic of the contemporary "significance of oil's geoculture in both its permeation of economic and political logic and its relatively autonomous persistence, as if it sits on the social as its truth in fiction." ${ }^{29}$ As Hitchcock has put it, oil is a way of life in both the past and the present of the "American Imaginary." For Worden, "Texas has endowed the petroleum industry, its public relations discourse, and its representations in fiction, television, and film with a rhetoric of heroic, frontier individualism that strives to cast even multinational corporations as wildcat operations. Oil culture is Texas culture." 30 The Permian Basin represents an ulterior specification of this phenomenon, namely Texan petroculture on steroids. Here, petroleum has been interwoven for decades with the geocultural identity of the locals. It is an economic and socio-political priority that attracts constant attention and occupies a lot of space.

In this regard, there are two major cultural institutions that help frame and present the narrative of the Permian Basin. In Odessa, the University of Texas of the Permian Basin (UTPB) forms the ranks of what Szeman calls "oil capitalism," 31 in this case the skilled workers, engineers, and geologists capable of promoting the shale revolution (Picture 6). The second institution that constitutes a symbolic and powerful showcase of pride and entrepreneurial spirit is The Permian Basin Petroleum Museum (PBPM). Its informative and well-designed expositions do more than simply educate the visitors about oil and the fluctuation between hope and despair in the Permian Basin. The narrative of the museum praises the rugged individualism of some courageous and inventive white men who tamed the black gold, but it often transitions into unquestioned, blunt propaganda. As Abby Spinak observes in "The Twenty-

\footnotetext{
${ }^{28}$ Frederick Jackson Turner, The Frontier in American History (New York: Henry Holt and Co, 1920).

${ }^{29}$ Hitchcock, 97.

${ }^{30}$ Worden, 350.

${ }^{31}$ Imre Szeman, "System Failure: Oil, Futurity, and the Anticipation of Disaster," South Atlantic Quarterly 106, no. 4 (2007): 806.
} 
first Century Oil

Encounter: Dispatches from Texas," the oil industry has intensified public outreach, fostering what she calls an "inclusive approach." The museum suggests the idea that "oil has room for everyone and is synergistic with 'nature'."32 The PBPM also features a section on non-fossil-fuel energy, but instead of being labeled with typical adjectives such as "sustainable," "clean," or "renewable," it is titled "supplemental energy" (Picture 7). Similarly to the Drake Memorial studied by Ross Barrett (2012), the PBPM offers "a promotional culture of the early [and current] petroleum industry that explores the intersections between the traditional arts and industry publicity and illuminates the vital role that cultural representations played in accommodating twentieth-century Americans to the dynamic structures of petro-capitalism." 33 For example, an entire area of the museum is devoted to the theme "petroleum goes on air" and concerns the efforts of the petroleum industry toward advertising. Overall, the Petroleum Museum serves multiple purposes: as a place of remembrance and conservation, it commemorates the complex history of fossil fuel extraction in the region; as a didactic outlet, it informs and educates; and as a propaganda machine, it tacitly reinforces a narrative.

\footnotetext{
${ }^{32}$ Abby Spinak, "The Twenty-First Century Oil Encounter: Dispatches from Texas," Society to the History of Technology, August 27, 2017, https://www.technologystories.org/the-twentyfirst-century-oil-encounter-dispatches-from-texas/.

${ }^{33}$ Barrett, 395.
} 


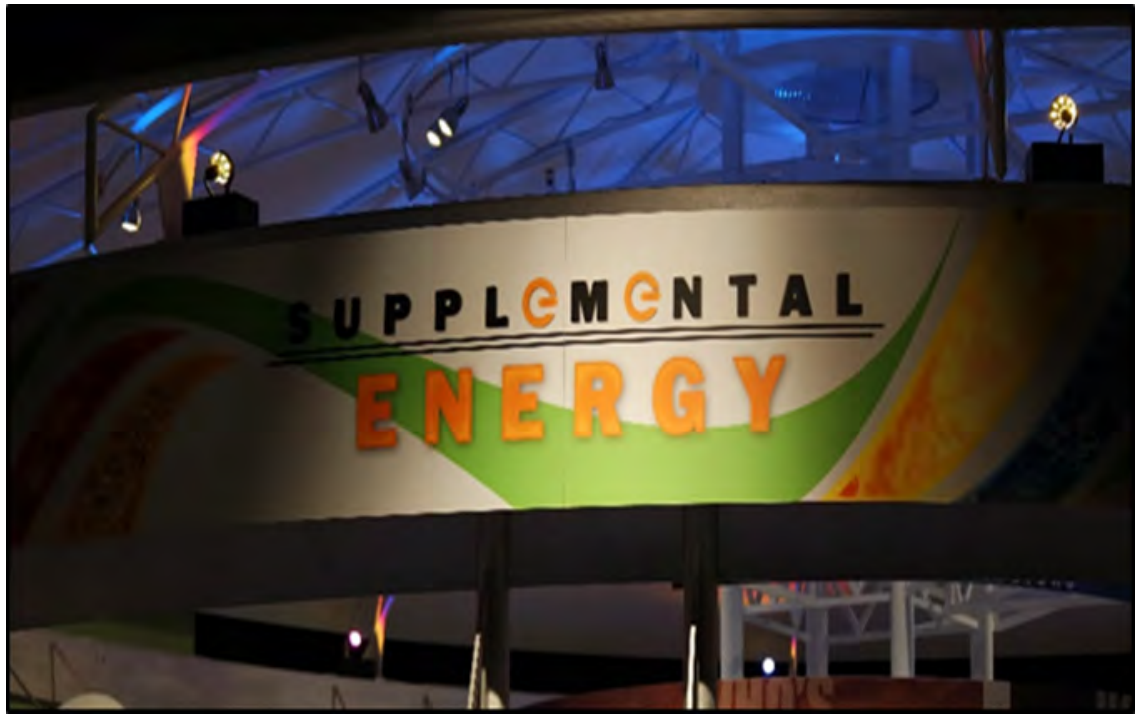

Picture 7: Areas of the Petroleum Museum devoted to "supplemental" energy

\section{Billboards as Petromedia}

Besides the university, the Million Barrel Museum, and the PBPM, the petroculture of West Texas is visible along the highway that leads past countless drilling operations. There, billboards function as specific petromedia that successfully fulfill their purposes: impress, influence, and, sometimes, deceive. After all, these are the main goals of such advertisements since their inception as billpostings in the late $1700 \mathrm{~s} .{ }^{34}$ As soon as oil became a commodity, the industry has been supporting advertising, and, in turn, patronizing arts for their creativity and efficacy in creating believable messages. In this sense, visual arts and billboards have long ago "established the key terms for a promotional discourse that would circulate throughout the twentieth century." 35

In her compelling book Buyways: Billboards, Automobiles, and the American Landscape, Catherine Cudis moves from the history and evolution of billboards to investigate specific cultural aspects of North America. She clarifies that modern-day billboards should be understood in relation to art but especially within the context of consumerism that emerged during the $19^{\text {th }}$ century, when outdoor marketing became a major outlet to ensure companies'

\footnotetext{
${ }^{34}$ Randy Schueller, “Billboard,” Encyclopedia.com, How Products Are Made, October 22, 2019.

35 Barrett, 395.
} 
visibility. For example, she shows that the invention of the electric billboard during the early 1900s merged the function of advertising with that of lighting up cities. This apparently simple development was conducive to the birth of nightlife, a phenomenon that granted more time for sociability and extended the hours available for consumption, thus combining multiple purposes. With specific regard to road ads, Cudis shows the reasons and implications of producing "mobile audiences and corridors of consumption":

As the car came to be a routine part of the American way, the highway also became more than merely a route to be traveled. Among other things, the road now comprised a boundless marketplace "millions of miles long" and billions of dollars strong that with every year burst farther out of its traditional confinement within town and city boundaries. Broadway, Fifth Avenue, and Main Street might once have been the commercial centers for business and trade, but in the age of the automobile all highways were now destined to serve that function. The highway had become the "buyway." 36

But the core of Cudis' book discusses the evolution of American "mobility on wheels" in parallel to that of consumerism, highlighting the powerful history of billboards in shaping a specific car culture that is closely woven to both the "American Way of Life" and to policy. It took advertisements, automobiles and highways to "decentralize the market so that it is now virtually everywhere." In this way, they have "altered the ways we experience very basic things, including nature, the landscape, community, images, words, architecture, and even abstract space and time.",37

Similar dramatic changes in the landscape are further explored by Matthew T. Huber who stresses that since "space is both socially and ecologically produced [it is evident that] the lived practices of energy consumption actively make possible specific spatial configurations of residential settlement, transportation networks, and the global flows of commodities." 38 In sum, the development of the interstate system, the invention of the internal combustion engine, the emergence of the automobile culture, and the booming of road advertising are interlinked phenomena that are at the same time causes and effects of the progressive switch from coalcapitalism to oil-capitalism.

\footnotetext{
${ }^{36}$ Cudis, 1.

${ }^{37}$ Ibid., 3.

${ }^{38}$ Huber, Lifeblood, 103.
} 
Now that we have briefly contextualized billboards as petromedia, let us consider their materiality. Most of the billboards considered here stand on infrastructures owned by Lamar Advertising, founded in 1902 in Pensacola, Florida. They mostly belong to the "bulletin" type, a standard-sized billboard that typically measures 14 feet high $(4.3 \mathrm{~m})$ and 48 feet wide $(14.6 \mathrm{~m})$, a size that appears "normal" to any driver but is gigantic once approached outside of a speeding vehicle. Even though these billboards are ubiquitous, they seem to be invisible objects as their material presence has become an integral part of the landscape. In Understanding Media (1994), Marshall McLuhan warned about the fact that very often we fail to recognize and remember the structural changes in our lifestyles that were introduced subtly or over long periods of time, and this seems to hold with billboards as well. What has become invisible to many is the fact that billboards are there for a reason. They are there to convince, symbolize, suggest, and even prescribe something to the drivers. It is in this sense that I claim that the billboards of West Texas continuously reproduce a narrative that has become habitual: the fossil bounty underneath the surface must be extracted, profit must be gained, and this is, overall, positive and pride-inducing. The fact that this story is unquestioned makes it problematic from a political standpoint. Billboards are not value-free artefacts. They reinforce a specific philosophy through the use of comforting values still connected to a sort of pioneering spirit of the frontier: freedom, pride for what has been accomplished, and excited hope for what is coming. And these ideas are retrievable in the billboards which mirror back to the drivers an anthropocentric narrative of individualistic and greedy conquest, courage, and manliness, reinforcing a specific identity and worldview. It is in this sense that billboards are compelling petromedia to learn and "know about oil" and its influence in shaping landscapes, spaces, and lifestyles. ${ }^{39}$

A simple but not trivial aspect to consider is that billboards convey messages. The way the message is conceptually put together, linguistically construed and then designed on the billboard can offer further insights about the intentions behind the advertisement itself. Back in the 1960s, during the boom of advertisements in Western countries, Marshall McLuhan famously wrote that "the medium is the message," 40 stressing that a medium in itself, not only the content it carries, should be the focus of thorough study. Moving from McLuhan's suggestion, the study of petroleum-related billboards helps

\footnotetext{
${ }^{39}$ Imre Szeman, "How to Know about Oil: Energy Epistemologies and Political Futures," Journal of Canadian Studies 47, no. 3 (2013): 145-68.

${ }^{40}$ Marshall McLuhan and Quentin Fiore, "The Medium Is the Massage," in The Medium Is the Massage: An Inventory of Effects (London: Penguin Books, 1967), 7-21.
} 
understand some of the assumptions and the values of the culture that produces them. In this sense, billboards are media that both mediate and are mediated. For instance, billboards are huge structures that emerge from the soil carrying strong statements, straightforward declarations that are not open for dialogue. Advertisements must be bold, unequivocal, and display no hesitation. Despite the wind blowing through the prairies, the billboards stand strong and affirmative. For these reasons, the choice of specific fonts and colors are carefully decided and mirror the subtle social psychology behind the texts and their subliminal meanings. This design psychology is not only dependent on advertising efficacy. In the case of West Texas, petromedia either romanticize oil and gas extraction or highlight traits such as strength, precision, reliability, and pride.

From a design perspective, fonts, sizes, colors, and backgrounds all matter, and carry a variety of different meanings that mediate a way of thinking. They communicate drivers an unequivocal message: we are here to work hard for America. Sometimes the simplicity of the design suggests a type of frugality, a reduction of the means of communication to the bare minimum, sparing the bells and whistles for later, when the profits of the shale will allow for a more colourful scenery elsewhere. Many of the examples in the following pages are written with fonts that have significant weight (the thickness of the character outlines relative to their height), signifying a robust, firm statement. The fonts are typically written in bold uppercase letters, using sans-serif fonts. This strong, clean style increases the sense of stability and objectivity. In fact, it has been shown that familiar, simple, and clear fonts increase fluency of judgment and reduce its deferral, ${ }^{41}$ thus preventing distraction in the reader and improving trust in the product. Billboards frequently span over 20 feet $(6 \mathrm{~m})$ in width and the most common are much larger so that legibility is not sacrificed.

From a syntactic standpoint, billboards are concise and clear in their form, and are expected to be persuasive. Another key aspect is of course semantics: terminology, symbolism, and syntax can be either very simplistic or subtly designed to convey more nuanced messages. Often the billboards are minimalist, displaying simple terms on a white board. In those cases, the absence of pictures or backgrounds also communicates a message of pragmatic engagement with reality at the expense of aesthetic pleasure. Some boards make use of symbols or drawings that exploit the metaphorical meaning of animals (e.g. rampant stallion) or other natural phenomena such as drops (of oil) or flows of matter, signifying the movement of petroleum through endless

${ }^{41}$ Nathan Novemsky et al., "Preference Fluency in Choice," Journal of Marketing Research 44, no. 3 (2007): 350. 
pipelines. Mythology and the past are sources of inspiration too, so that Vikings, Giants, Titans, Dragons, and Greek deities are invoked in support of the slogans. In this respect, billboards contain profound subliminal and cultural references that help understand the complexity of this petroculture.

McLuhan metaphorically describes this deceptive strategy as a process of signification: "the 'content' of a medium is like the juicy piece of meat carried by the burglar to distract the watchdog of the mind."42 Similarly, outdoor marketing in West Texas catches drivers' attention through cultural references that symbolize the successes and benefits of oil and gas extraction but do not show any of the downsides of the shale revolution. The billboards of West Texas may have an actual impact on people because they shape "the scale and form of human association and action," as McLuhan puts it. In his terms this happens because "the content of any medium is always another medium," 43 and so the various items and services advertised on the billboards may determine concrete actions. These associations derive from the semantic content of the billboards: impact, expertise, strength, reliability, precision, toughness, experience, and other terms that connote a precise techno-scientific, mechanistic, masculine, and anthropocentric worldview. These assumptions have cemented practices, actions, and policies that are coherent with that philosophy but problematic in a time of energy transition and pressing environmental issues. Still, the open prairies of West Texas are perceived as an Eldorado that is meant to be dug up, fracked with sands and chemicals, and exploited as much as possible. The billboards indirectly tell the story of the exploitation of nature for the sake of human economic prosperity, thus providing an indirect justification of such conduct through its normalization.

Finally, billboards can be seen as undesirable forms of pollution alongside the noises of drilling operations or the smells of a refinery. Even though they are taken for granted, road ads are neither requested nor explicitly desired by the public. They become part of the landscape in a forceful manner and this aspect applies to all roadside advertisements, related or not to fossil fuels. In fact, the issue of visual pollution becomes clear when we consider the fact that some states have taken measures to reduce or even ban road ads altogether. As noted by the President of Nomad Communications, Alex Kahan, "Hawaii was the first state to ban billboards in the 1920s, Vermont in 1968,

\footnotetext{
42 Marshall McLuhan, Understanding Media: The Extensions of Man (Cambridge, MA: The MIT Press, 1994 [1964]), 18.

${ }^{43}$ Ibid., 9.
} 
Maine in the early 80s, and Alaska (by state referendum) in 1998." ${ }^{44}$ In general, the visual dominance of giant advertisements may overwhelm the traveler and affect the complete visibility of the surroundings. ${ }^{45}$ Multiple sociopolitical issues connected to billboards are becoming especially relevant as the shift from traditional to hi-tech advertisements takes place. ${ }^{46}$ While the illumination of traditional outdoor marketing is static, newer billboards are increasingly using dynamic content that changes through mechanic movement or, more recently, are employing giant LED screens with animations and vivid colors. This is raising concerns regarding the effects on drivers' safety due to the fact that billboards may negatively affect field of vision ${ }^{47}$ and impair driving. ${ }^{48}$

\section{Petrocultures on the Billboard}

While approaching the core of the Permian Basin, and especially after Big Spring and its gigantic refinery, ${ }^{49}$ the distinctive smell of oil becomes more intense and progressively invades your nostrils. In this way, the encounter with fossil fuels becomes even more perceptible and provokes in some people a mild sensation of dizziness. Here is where the businesses connected to the petroleum boom publicly advertise their goods and services: exploration, survey, safety training, legal services, workers' accommodation, food and drinks, and different sorts of entertainment. In the Permian Basin, advertisements can refer as much to quintessential Texan institutions like the

${ }^{44}$ Alex Kahan, "Four States That Ban Billboards—Who? What Does It Mean?" Nomad Communications, 2017, http://blog.nomadcommunications.com/blog/four-states-that-banbillboards-who-what-does-it-mean.

45 Jessica Edquist et al., "Effects of Advertising Billboards During Simulated Driving," Applied Ergonomics 42, no. 4 (2011): 624.

${ }^{46}$ Osborne, Anne C., and Renita Coleman, “Outdoor Advertising Recall: A Comparison of Newer Technology and Traditional Billboards," Journal of Current Issues and Research in Advertising 30, no. 1 (2008): 13-30.

${ }^{47}$ Wandachowicz, Krzysztof. "Examination of Luminance Distributions in the Field of Vision of Drivers in Locations with LED Billboards." PRZEGLADD ELEKTROTECHNICZNY, no. 8 (2013): 270-73.

${ }^{48}$ Edquist et al., 619-26.

${ }^{49}$ It is worth noting, with Matthew T. Huber, that "A precondition of a petroleum-intensive social formation is, of course, substantial refining capacity [and the United States] emerged from World War II as a perfected petro-capitalist social formation with immense material infrastructure for the mass production and consumption of petroleum" (98). The situation is indeed quite different in countries rich in oil reservoirs but lacking large refining capacity such as Venezuela. 
steakhouse, as to divinities, mythologies, and animals so to publicize the "exuberance" of oil and gas-related enterprises. ${ }^{50}$ Matthew Huber's monograph Lifeblood has already investigated oil and gas interest in advertising to shape northern American petroculture as well as what he calls "entrepreneurial life." Moreover, Huber demonstrates that

the ecological basis of the vast geography of individuated choice over where to live and travel was predicated upon not just the gasoline to actively fuel automated mobility but also a wider set of petroleum products that provisioned and lubricated the infrastructures of suburban mobility. ${ }^{51}$

For a long time, oil companies have been stressing how influential and necessary they are, for they provide not only the essentials of power and transportation, but also an infinite set of "material supplements to the car-road assemblage that actively constituted the experience of mass automobility." For example, Huber recalls the straightforward message of an Esso Oil (later Exxon) advertisement from 1950 that stated: "Petroleum helps to build a better life." The centrality of petroleum associated with the notion of freedom of movement have become core values and, eventually, entitlements for the North American middle class. Unrestrained mobility in the era of individualism means unlimited mileage in a personal vehicle, a type of freedom that is so central to the "American way of life." Hence, fossil fuels, plastics, and countless derivative products constitute both the precondition and the reason for the expansion and perpetuation of a specific type of mobility and politics. Accordingly, Huber affirms that

Oil advertisements like these attempted to remind drivers that their individual power to conquer space could be "taken for granted" and was, in fact, impossible without the "important role that petroleum products are playing in the development of better living standard everywhere." This particular strategy served to make petroleum products the foundation of entrepreneurial life, where life was imagined as what you make of it, but without petroleum your individual ability to make anything would vanish. $^{53}$

\footnotetext{
${ }^{50}$ Buell, 275.

${ }^{51}$ Huber, Lifeblood, 106.

${ }^{52}$ Ibid.

${ }^{53}$ Ibid., 106-107.
} 
But, as already anticipated above, this sort of alliance between cars, fossil fuels, and roads ultimately depends on assumed ideas and values, which can be traced back to the modern period and are essentially a western legacy.

Recalling my initial thesis, I propose that many billboards are based on a specific philosophy of energy grounded in the scientific and Western notion of energy that emerged during the eighteenth century. In this sense, these petromedia imply several key cultural and philosophical elements that have characterized the energy-human-nature relationship throughout modernity, a theme that I have explored elsewhere. ${ }^{54}$ Consequently, I suggest here that, on the one hand, billboards, signs, and posters embed and display the idea that what is meant by "energy" is essentially fossil fuels. On the other hand, the analysis of their design and content allows for a novel way of understanding "petromedia" to make sense of the visible (e.g., billboards, trucks), the invisible (e.g., hundreds of miles of hidden pipelines), and the symbolic (the cultural values at stake).

Although petroleum advertising comes in many forms, in the following and final section I will analyze several billboards, posters, and other highway signs with the support of photographic evidence. This survey proposes a reflection on the specificity of these petromedia. Their language and aesthetic features demonstrate how oil and gas are embedded in the culture of West Texas, and arguably North America in general. By telling the story of this linguistic and conceptual entanglement, this section highlights the aesthetic landscape and the visual rhetoric of oil country. I group these advertisements into three categories according to the type of business advertised or the specificity of the ads' content. For many of the billboards, I also report information that is publicly available through the companies' websites, which I sometimes quote or cite accordingly. The billboards listed in the following sections have been collected along I-20 and some surrounding roads in late March 2018, within the counties of Howard (city: Big Spring), Midland (homonym city), and Ector (city: Odessa), all located in West Texas.

\subsection{Oil, Bar-B-Q, \& Chains}

The first category of billboards does not have to do with petroleum directly but is nonetheless intertwined with the social values of local lifestyles directly tied to oil and gas. Rolling along I-20, all the traditional landmarks of the "Lone Star State" appear in the landscape. Vast prairies spotted with shrubs

${ }^{54}$ Giovanni Frigo, "Energy Ethics, Homogenization, and Hegemony: A Reflection on the Traditional Energy Paradigm,” Energy Research \& Social Science 30 (June 2017): 7-17. 
progressively open to more drilling developments and constructions. Tall water towers rise high upon the horizon, proudly showing the name of the city they serve. Anonymous malls and ever-present chains dominate the retail and food sectors. The external appearance of these buildings makes impossible any spatial or geographic orientation. The same features, landscaping, the same immense parking lots of the usual big-box stores like Walmart, Lowe's, or Home Depot. And dozens of cars, trucks, and RV dealerships, along with rentals and temporary camping grounds. This scenery is illustrative of what sociologist Jean Baudrillard described as "the humour of the mobile home and the giant hamburger on the sixteenfoot long billboard, the pop and hyper humour so characteristic of the atmosphere of America." 55 The landscape continuously reminds the traveler that the American Way is essentially nomadic, as much as the constant moving around of trailers, trucks, and drilling equipment to find and pump out of the ground more and more oil and gas. The advertisements of many trucking companies underlie the urgency implied by their task: "Rush-Over-Land" or the more basic (and telling) "Rush". They reassure the potential contractors that reliability and timing are their priority, no matter what. This category of billboards includes technical clothing such as

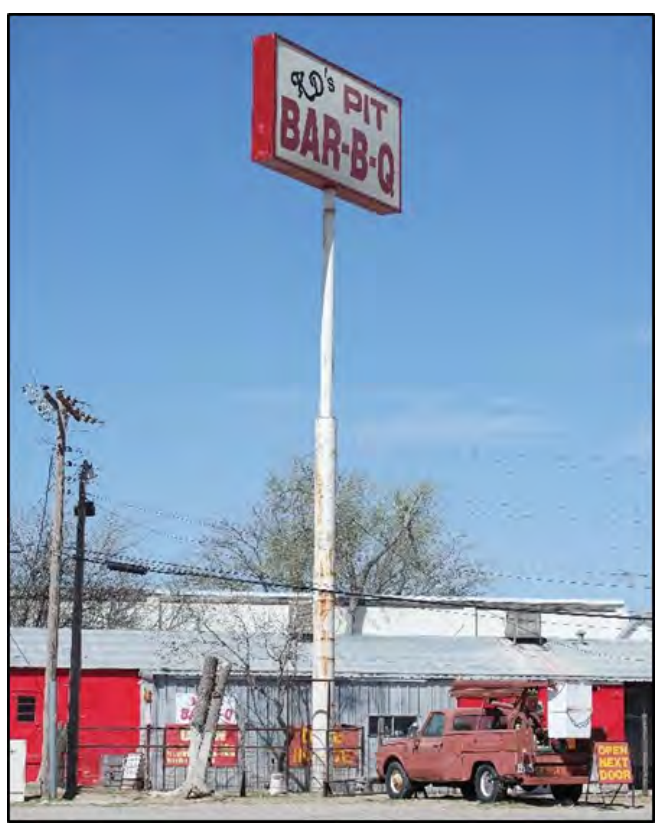

Picture 8: Pit Barb-B-Q in Midland, TX boots shops, but a major focus is food, tons of food. Tex-Mex and American diners compete with the predictable, notorious main chains such as Taco Bell, McDonalds, or Jack in the Box. Juicy pictures color the advertisements of steakhouses and self-declared "worldrenowned" Bar-B-Qs, which endlessly promise Texas-size cuts of meat. Many of them appeal to Spanish/Latino-sounding names ("Carambas Spanish Inn," "Mamacita's Mexican Grill," "Dumplins Y Amigos") or comforting rhymes such as "Steak and Shake." Holes in the ground can serve different purposes, so besides the reserve pit and the mud pit (used to collect spent drilling fluids,

\footnotetext{
55 Jean Baudrillard, America, trans. Chris Turner (New York: Verso, 1989[1988]), 86.
} 
cutting, and wash water during drilling operations) there is "KD's Pit Bar-B-Q" serving the best smoked ribs in town-so a local told me (Picture 8).

\subsection{Technoscience and Drilling}

The second category of billboards is the properly techno-scientific one. These advertisements stress expertise and skillfulness (Picture 9), responsiveness and effectiveness, accuracy and precision (Picture 10). A billboard that is frequently seen all

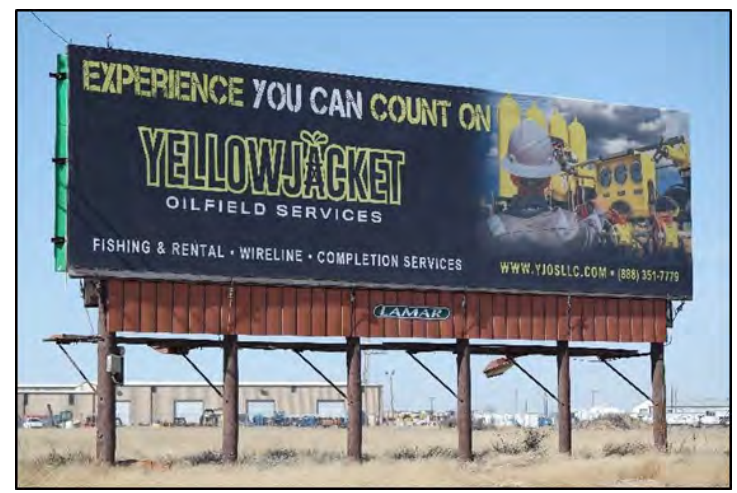
over the States but is particularly relevant in this region concerns the risks of uncharted excavations. Accordingly, this notorious billboard states: "Know what's Below. Call 811 Before you Dig" (Picture 11). Given the Picture 9: Experience is pivotal in Oil Country extension, length, and intricacy of the 2.4 million miles of pipeline systems in the US, it sounds like reasonable advice. Two main points are constantly stressed in oil and gas ad campaigns: the ability to innovate and a long-term story of successful achievements. Most companies state on their websites the cumulative years of experience of each team: 75 years, 130 years, and so forth. A board at the Petroleum Museum mentioned a local motto according to which "a contractor's reputation is 'as good as their last job' so doing your very best work every day is essential." The ideas of consistency, perfectionism, and reliability are key traits of a good worker here.

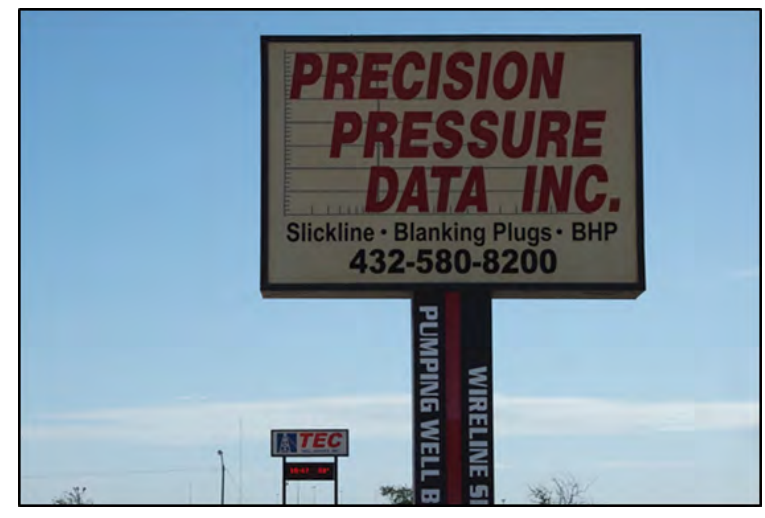

Picture 10: You need precision to find the shale and to avoid that excessive pressure blows up the pipe 


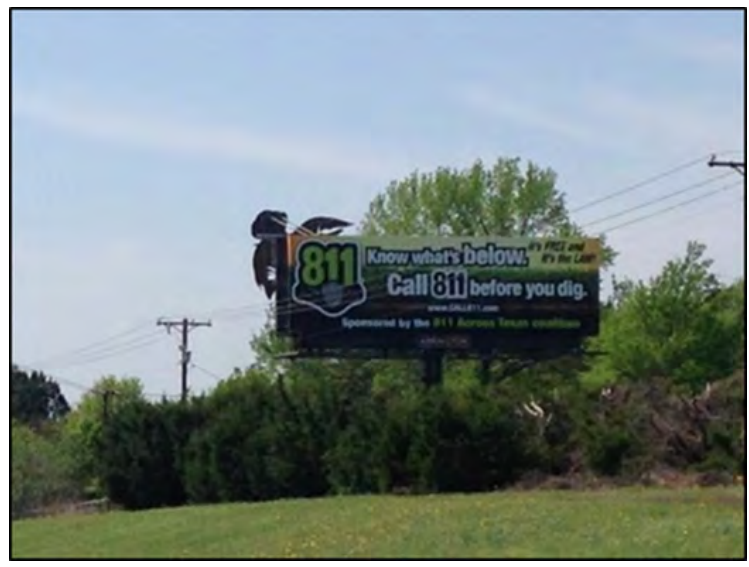

Picture 11: The common public safety billboard "811"

"Gravity" is a company that provides high profile field services such as water supply, power generation, and wellbore solutions (a hole that is drilled to aid in the exploration and recovery of natural resources including oil, gas or water). Their website states it clearly: "When equipment is stranded downhole, operators can count on Gravity to get it out and keep them producing. With specialized, quality equipment, highly trained crews, well-developed infrastructure, and multiple locations where it counts, Gravity is the go-to team." The "A" and "V" in "grAVity" become a continuous flow because, as Gravity's homepage proudly affirms, "in the oilfield,

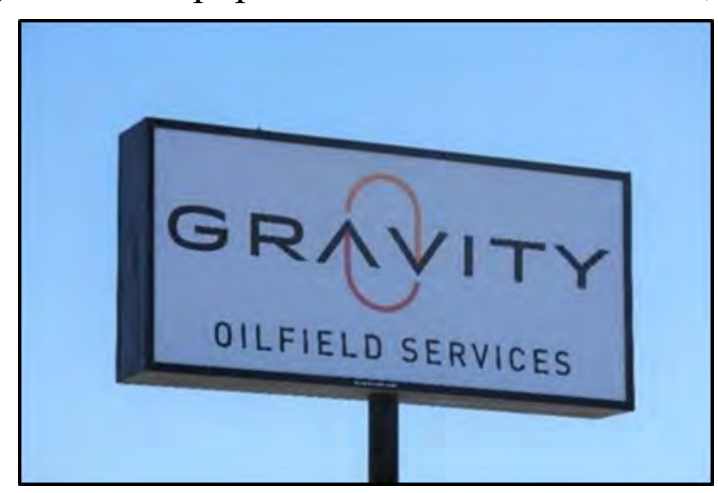

Picture 12: Gravity, in Odessa, TX GRAVITY IS THE UNDENIABLE FORCE, the unbroken promise and the uninterrupted flow" ${ }^{56}$ (Picture 12).

An indirect reference to a major socio-political conundrum-American relations with Mexico - can be found in the energetic board of "Viva" Energy Services (literally "Hurrah" or "Long Live"). This board perhaps appeals to the many Mexican workers in the area by using Spanish and a warm, earthly

56 “Oilfield Services| Gravity Oilfield... | Gravity Oilfield Services," Gravity Oilfield Services, www.gravityoilfieldservices.com. 
orange tint (Picture 13). C\&J Energy Services shows a picture of a worker tightening a bolt on a rig and puts the main argument in clear characters:

"DELIVERING EVERY TIME." where the full stop is a big squared mark that instills trust (Picture 14). As far as I could tell, Emerson is the only company that refers to "going green" in its advertising of the "Enardo ES-665 thief hatch for tighter emission control." The ad is unique in that it displays a picture of a pump jack "sweating" under a shiny sun (Picture 15). For anyone who still has doubts about how effective the drilling operation are out here, there is "Impact! Chemical Technologies, Inc.," which on its website plays with letters and symbols by writing: "IMPACT! ing the Petroleum Industry" 57 (Picture 16). Indeed, if we turn to the Energy Information Administration's (EIA) Drilling Report, we can see that although the legacy oil and natural gas production change has been constantly decreasing between 2009 and 2018, both the annual and the cumulative amounts of oil and gas produced in the same period have been constantly increasing (see Appendix 1).

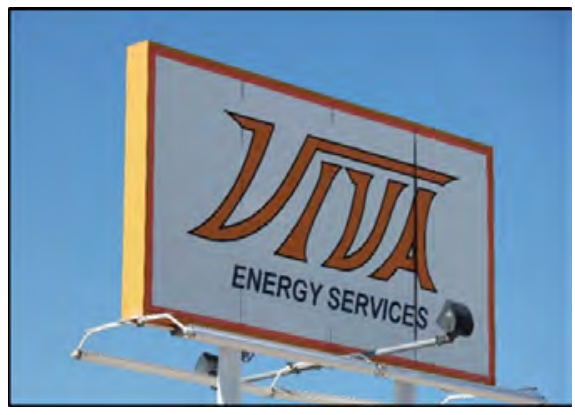

Picture 13: Hurrah! We found more oil, cheer up! In Odessa, TX

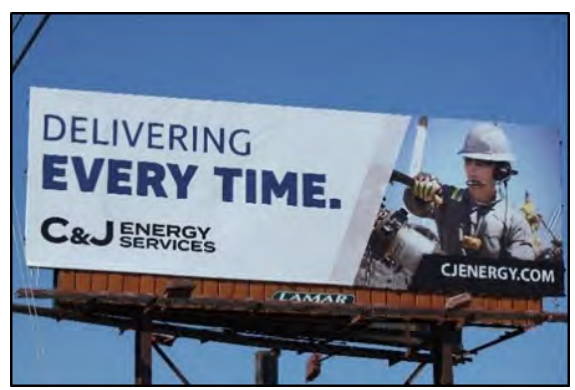

Picture 14: Dependability and consistence dominate in this billboard of C\&J Energy Services

57 "IMPACT! Chemical Technologies, Inc | Impacting the Petroleum Industry," IMPACT! Chemical Technologies, Inc, http://impactchem.com. 


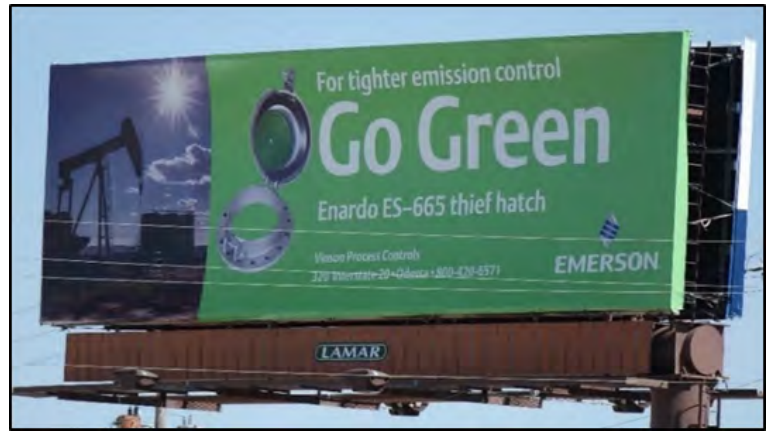

Picture 15: A sunny, clear sky without too much emission guarantees Emerson in Midland, TX

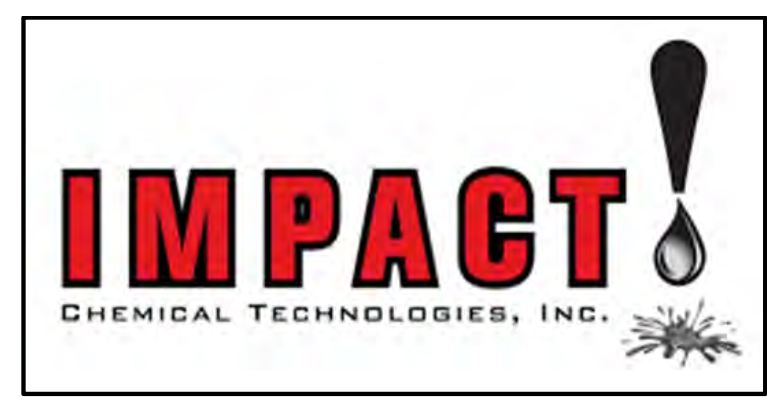

Picture 16: Impact Chemical Technologies, based in Midland, TX

\subsection{Animals, Mythology, and Divine Beings}

A third, rather fascinating category of billboards that caught my attention consists of the petroculture's appropriation of specific animal traits to convey a metaphorical association between key characteristic and values commonly attributed to a certain animal and the companies' desired public appearance. These boards are not, of course, concerned about animal ethics or rights. Rather, they promote a clever exploitation of the cultural power of specific species to symbolize the values contained in the message. "Toro Services" (Spanish for "bull") is a transport company in Odessa. "Wild Cats Oil Tools" reminds the traveler and client of the emblematic spirit of "wildcatters," the courageous individuals who have been sinking exploratory wells (a.k.a. wildcat wells) in areas not known to be oil fields (yet). A warehouse of heavy-duty tools is named after a virile and rampant animal, the "Stallion," which expresses the tough kind of masculinity required to work in the oilfields (Picture 17). The use of the horse is even more ironic considering that oil and gas explorations have been possible through the process of enclosure, or 
privatization of property, and through the exploitation and confinement of horses. This is a case in which billboards, probably unknowingly even to the designer, tell a deceiving story about the past in order to embellish a glorious present. It seems that collective imagination still envisions Mustangs as forceful animals running free

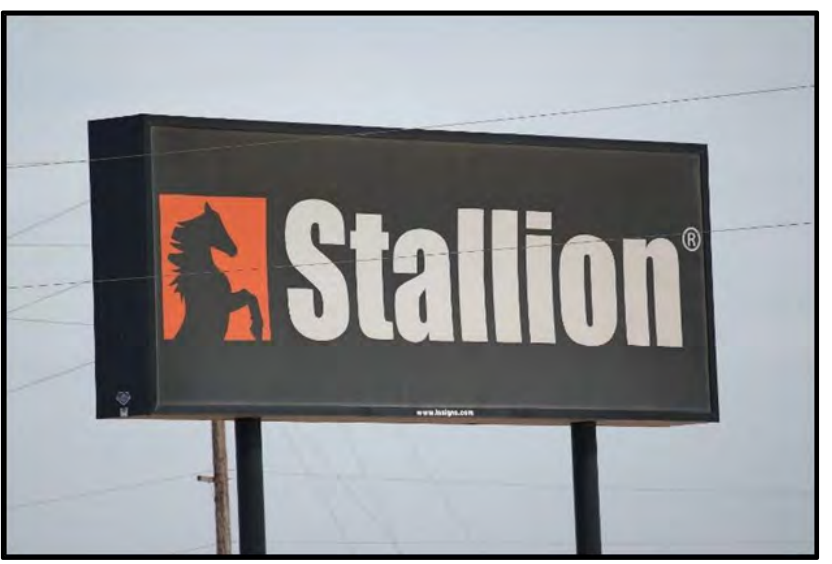

Picture 17: The rampant stallion is ready to be unleashed in Midland, $T X$ in the open of the great prairies - no matter if the land is mostly fenced and leased to oil and gas contractors. The entanglement between human and nonhuman life is also evident in the overall presumed human victory over nature. Vadén and Salminen, for example, point out that this idea of human superiority - an emblem of modern Western thinking - is "supremely ironic" because its essential material conditions depend on fossil fuels, a very natural occurrence. ${ }^{58}$

Furthermore, there are billboards that refer to a powerful and ancient past, depicting rather incredible characters given the actual context. Most of the time, the promoters of these boards are also enterprises devoted to a myriad of "field services." The companies are often named after something or someone that is

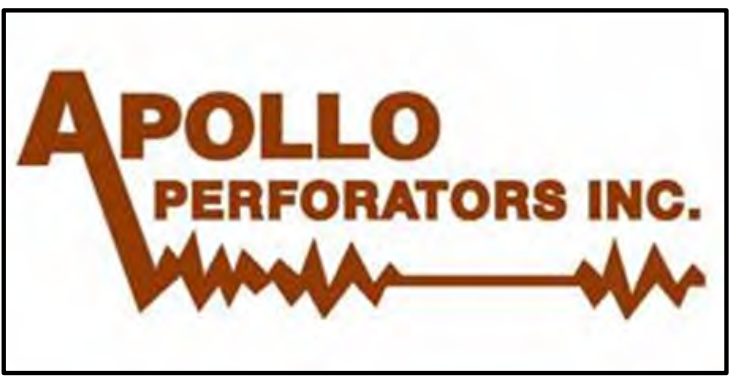

Picture 18: A spatial mission or a Greek god are the inspiration for this experienced family-owned business in Odessa, TX. Source: http://www.apolloperforators.com still in some sense culturally relevant, even though the connection is (most of the time) completely forgotten. The examples abound, and they span from Greek and Norse mythologies to an imaginary world of dragons. There is the family-owned and proudly operated for over 37 years "Apollo Perforators, Inc." (Picture 18), which is either a connection to the spatial explorations from

\footnotetext{
58 Tere Vadén and Antti Salminen, "Ethics, Nafthism, and the Fossil Subject," Relations: Beyond Anthropocentrism 6, no. 1 (2018): 41.
} 
Houston to the Moon, or to the Greek god of music, truth, and prophecy. Indeed, many prophecies have been made about oil peaks and shortages, but the son of Zeus and Leto apparently helped contractors and engineers overcome many of them. Just a few feet away, "SoGiant Pumping Services" promises technical support the size of Texas, following in the steps of a race of human form but superhuman size, renowned for its great strength and aggression according to both Norse and Greco-Roman mythologies. And then one of my favorites, "Titan PetroServices, LLC" (Picture 19). In this case, the children of the primordial deities Uranus (heaven) and Gaia (earth) are invoked by a company specialized in providing "a complete package from start to finish," but also embellishing with Greek mythological references this bare land of oil exploration and incessant drilling. On top of the mythological references, there is "Dragon", which sells and provides equipment such as rigs, tanks, and separators "as TOUGH as the job they do" to quote one of their webpages (Picture 20). "Toughness" is a recurring theme, not only in the imagery and writing of the billboards, but also in the attitude of the many oilfield workers, mostly men, driving around in their oversized, heavy-duty pick-up trucks. Finally, a call to adventurous spirits can be found in "Viking Drilling, LLC," a privatelyowned oil \& gas drilling company (Picture 21). Perhaps, there is no better reference than the first Europeans to visit North America for naming a drilling

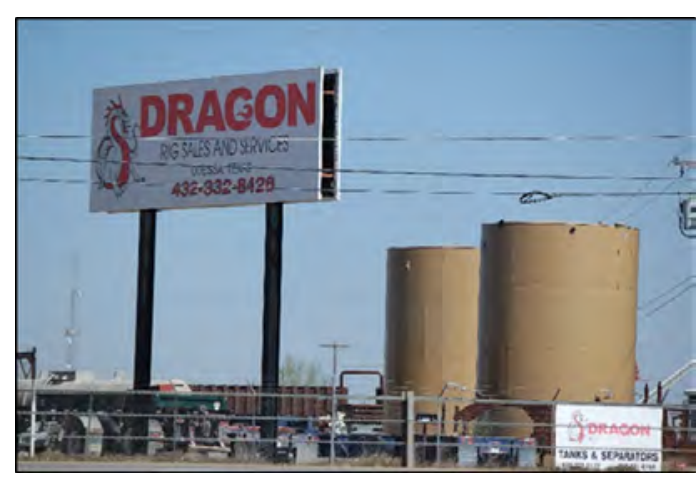

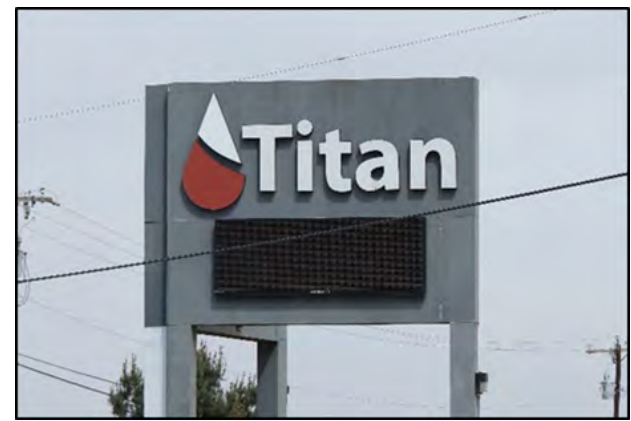

Picture 19: The oil drop is cut in two parts by the force of the Titan, in Midland, TX

company in West Texas: Norsemen from Scandinavia who courageously challenged the oceans on their longships to discover new lands to raid and to pillage.

Picture 20: The real risk of fire hazard does not discourage this Beaumont-based enterprise to continue the selling of drilling equipment 


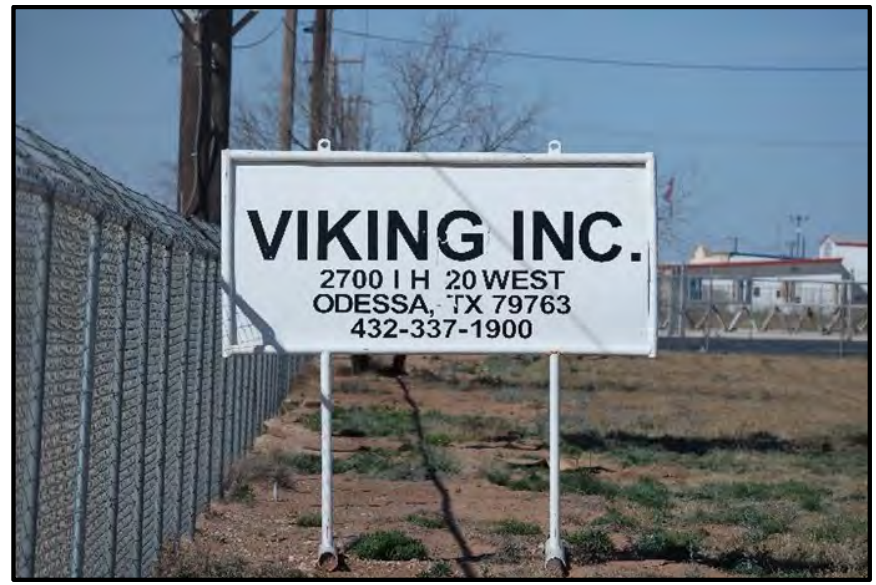

Picture 21: Viking Inc. recalls the explorations of the Northmen who were the first Europeans to discover North America

\section{Conclusion}

This article explored the petroculture of the Permian Basin by investigating the fundamental links between the emergence of the shale revolution and billboards as a specific type of petromedia. Moving from the documentary Shale Cowboys, I traced the beginning of the different techno-scientific breakthroughs that set the stage for the shale revolution. Then, turning more specifically to the Permian Basin of West Texas, I showed some of the ideas and values that constitute the underlying petro-philosophy of this fascinating region. The narrative of oil and gas in West Texas is both a mentality and a way of life that is still strongly connected to pioneering ideas such as "Manifest Destiny" and the "Frontier Out West." Travelling on I-20 from Dallas towards the boomtowns of Midland, Odessa, and Pecos offered the conditions for an intellectual encounter of sorts with the local petroculture. I explored the main technical and symbolic characteristics that can be found in the design, size, colour, and other features of these advertisements. At the core of the article, an analysis of several emblematic billboards helped articulate the thesis that the petroculture of the Permian Basin area — or its underlying "philosophy of energy" - is based on a conception of the energy-human-nature relationship that is strongly anthropocentric, instrumental, mechanistic, quantitative, and intrinsically linked to profit-making. The ideas and the values that fuel this understanding are multiple and depict a rather complex philosophical landscape. These preeminent cultural traits are connected to the culture of oil and gas extraction that is pervasive in the region and is having disruptive consequences worldwide. For instance, faith in technoscience, a nostalgic 
feeling for a glorious past nowadays connected to a sense of pride for the successes of the current shale revolution. Moreover, the article explored other key characteristics: individualism and reliance on private property rights, greed, masculinity and virility, a genuine passion for drilling and exploration, curiosity for the unknown, and stubbornness. Especially in the surroundings of the boomtowns of Midland and Odessa, the billboards tell a story that bridges the shale revolution to the America First Energy Plan of the current US Administration. Billboards are symbolic of the pervasiveness of fossil fuel extraction in the region but are also capable of unveiling a specific type of relationship between humans, nature, and energy. But what is perhaps most striking about what I witnessed in West Texas is the utter lack of diversity. For example, in the future local communities could challenge the monopoly of the oil and gas industry in the outdoor marketing of the Permian Basin. They could sponsor billboards that talk about exciting aspects of West Texas other than oil and gas. Alternative ads could provoke people to think more deeply about the connections between water usage and fracking, petroleum extraction and climate change, alcohol and drugs abuse and working conditions, namely issues that are extremely important but remain the hidden and seamier side of this petroculture. Until that happens, the billboards of West Texas stand strong against the dusty wind that sweeps the prairies, reminding the traveler that the petroculture of the Permian Basin is thriving.

\section{Acknowledgements}

This article has greatly benefitted from the insightful suggestions of Texas resident Mrs. Susan Seaborn, the assistance and feedback of Mrs. Elena Guerini, and the invaluable advice of Dr. Jordan Kinder. 


\section{Works Cited}

Aruga, Kentaka. "The U.S. Shale Gas Revolution and Its Effect on International Gas Markets." Journal of Unconventional Oil and Gas Resources 14 (2016): 1-5.

Barrett, Ross. "Picturing a Crude Past: Primitivism, Public Art, and Corporate Oil Promotion in the United States." Journal of American Studies 46, no. 2 (2012): 395-422.

Baudrillard, Jean. America. Translated by Chris Turner. New York: Verso, 1989 [1988].

Black, Brian. Crude Reality: Petroleum and World History. Lanham, MD: Rowman and Littlefield, 2012.

Boudet, Hilary S., Chad M. Zanocco, Peter D. Howe, and Christopher E. Clarke. "The Effect of Geographic Proximity to Unconventional Oil and Gas Development on Public Support for Hydraulic Fracturing." Risk Analysis 38, no. 9 (2018): 1871-90.

Boyer, Dominic, and Imre Szeman. "Breaking the Impasse: The Rise of Energy Humanities." University Affairs, February 12, 2014, https://www.universityaffairs.ca/opinion/in-my-opinion/the-rise-ofenergy-humanities/

Briggle, Adam. A Field Philosopher Guide to Fracking: How One Town Stood Up to Big Oil and Gas. New York: Liverlight Publishing Corporation, 2015.

Buell, Frederick. "A Short History of Oil Cultures: Or, the Marriage of Catastrophe and Exuberance." Journal of American Studies 46, no. 2 (2012): 273-93.

Cooper, Jasmin, Laurence Stamford, and Adisa Azapagic. "Shale Gas: A Review of the Economic, Environmental, and Social Sustainability." Energy Technology 4, no. 7 (2016): 772-92. 
Cudis, Catherine. Buyways: Billboards, Automobiles, and the American Landscape. London: Routledge, 2004.

Diamanti, Jeff and Brent Ryan Bellamy, eds. "Editors' Introduction: Envisioning the Energy Humanities." Reviews in Cultural Theory 6, no. 3 (2016): 1-4.

Dunaway, Finis. 2015. Seeing Green: The Use and Abuse of American Environmental Images. Chicago: University of Chicago Press.

Edquist, Jessica, Tim Horberry, Simon Hosking, and Ian Johnston. "Effects of Advertising Billboards During Simulated Driving." Applied Ergonomics 42, no. 4 (2011): 619-26.

Energy Information Agency (EIA). "Permian region natural gas prices fall as production continues to grow." EIA.gov, July 18, 2018. https://www.eia.gov/todayinenergy/detail.php?id=36673.

Fisher, M.K., J.R. Heinze, C.D. Harris, B.M. Davidson, C.A. Wright, and K.P. Dunn. "Optimizing Horizontal Completion Techniques in the Barnett Shale Using Microseismic Fracture Mapping." SPE Annual Technical Conference and Exhibition 90051 (2004): 1-11.

"Frack Free Denton | A project of the Denton Drilling Group," Frack Free Denton, http://frackfreedenton.org/.

Frigo, Giovanni. "Energy Ethics, Homogenization, and Hegemony: A Reflection on the Traditional Energy Paradigm." Energy Research \& Social Science 30 (June 2017): 7-17.

—. "Toward an Ecocentric Philosophy of Energy in a Time of Transition." PhD Dissertation, University of North Texas, 2018.

Fry, Matthew, Adam Briggle, and Jordan Kincaid. "Fracking and Environmental (In)Justice in a Texas City." Ecological Economics 117 (2015): 97-107. https://doi.org/10.1016/j.ecolecon.2015.06.012.

Gitelman, Lisa. "Media." In Fueling Culture: 101 Words for Energy and Environment, edited by Imre Szeman, Jennifer Wenzel, and Patricia Yaeger, 215-216. New York: Fordham University Press, 2017. 
Goldring, Hugh D. A., and Nicole Burton. The Beast: Making a Living on a Dying Planet. Edited by Patrick McCurdy. Grand Forks, ND: Digital Press at the University of North Dakota, 2018.

Haarstad, Håvard, and Tarje I. Wanvik. "Carbonscapes and Beyond: Conceptualizing the Instability of Oil Landscapes." Progress in Human Geography 41, no. 4 (2017): 432-50.

Hitchcock, Peter. "Oil in an American Imaginary." New Formations 69, no. 1 (2010): 81-97.

Huber, Matthew T. Lifeblood: Oil, Freedom, and the Forces of Capital. Minneapolis, MN: University of Minnesota Press, 2013.

_ . "Refined Politics: Petroleum Products, Neoliberalism, and the Ecology of Entrepreneurial Life." Journal of American Studies 46, no. 2 (May 2012): 295-312.

"IMPACT! Chemical Technologies, Inc | Impacting the Petroleum Industry." IMPACT! Chemical Technologies. Inc, http://impactchem.com.

Jones, Christopher. "Petromyopia: Oil and the Energy Humanities." Humanities 5, no. 2 (2016): 36.

Kahan, Alex. "Four States That Ban Billboards_-Who? What Does It Mean?" Nomad Communications, 2017. http://blog.nomadcommunications.com/blog/four-states-that-banbillboards-who-what-does-it-mean.

Lasfar, Nordin, dir. Shale Cowboys: Fracking under Trump. 2017; Netherlands: VPRO. https://www.youtube.com/watch?v=-IzgyM1r1y8.

LeMenager, Stephanie. Living Oil. Petroleum Culture in the American Century. Oxford: Oxford University Press, 2014.

Maugeri, Leonardo. “Oil: The Next Revolution.” Discussion Paper 2012-10. Cambridge, MA: Belfer Center for Science and International Affairs, Harvard Kennedy School, June 2012.

McLuhan, Marshall. Understanding Media: The Extensions of Man. Cambridge, MA: The MIT Press, 1994 [1964]. 
McLuhan, Marshall, and Quentin Fiore. "The Medium Is the Massage.” In The Medium Is the Massage: An Inventory of Effects, 7-21. London: Penguin Books, 1967.

Novemsky, Nathan, Ravi Dhar, Norbert Schwarz, and Itamar Simonson. "Preference Fluency in Choice." Journal of Marketing Research 44, no. 3 (2007): 347-56.

“Oilfield Services| Gravity Oilfield... | Gravity Oilfield Services.” Gravity Oilfield Services, www.gravityoilfieldservices.com

Osborne, Anne C., and Renita Coleman. "Outdoor Advertising Recall: A Comparison of Newer Technology and Traditional Billboards." Journal of Current Issues and Research in Advertising 30, no. 1 (2008): 13-30.

Paraskova, Tsvetana. "Coke, Meth and Booze: The Flip Side of the Permian Oil Boom.” OilPrice.com, July 29, 2018. https://oilprice.com/Energy/Crude-Oil/Coke-Meth-And-Booze-TheFlip-Side-Of-The-Permian-Oil-Boom.html.

Rach, N. M. "What a typical small operator experience in the Barnett shale play." Oil \& Gas Journal 102, no. 3 (2004): 46-50.

Schueller, Randy. "Billboard." Encyclopedia.com. How Products Are Made, October 22, 2019. https://www.encyclopedia.com/literature-andarts/performing-arts/theater/billboard.

Sinclair, Upton. 1927. Oil! New York: Albert \& Charles Boni Publishing Company.

Spinak, Abby. "The Twenty-First Century Oil Encounter: Dispatches from Texas." Society to the History of Technology, August 27, 2017. https://www.technologystories.org/the-twenty-first-century-oilencounter-dispatches-from-texas/.

Stevens, Paul. "The 'Shale Gas Revolution': Developments and Changes." Chatham House Briefing Paper 4 (August 2012): 1-12.

Suchy, D.R., and K.D. Newell. "Hydraulic Fracturing of Oil and Gas Wells in Kansas." Kansas Geological Survey Public Information Circular 32 (May 2012): 1-6. 
Szeman, Imre. "System Failure: Oil, Futurity, and the Anticipation of Disaster." South Atlantic Quarterly 106, no. 4 (2007): 805-23.

_. "How to Know about Oil: Energy Epistemologies and Political Futures." Journal of Canadian Studies 47, no. 3 (2013): 145-68.

—_. "On the Energy Humanities; or, What Can Philosophy Tell Us About Oil?" European Union Centre of Excellence Working Papers 1 (2015): $1-22$.

- On Petrocultures: Globalization, Culture, and Energy. Morgantown, WV: West Virginia University Press, 2019.

Szeman, Imre, and Dominic Boyer, eds. Energy Humanities: An Anthology. Baltimore: Johns Hopkins University Press, 2017.

Szeman, Imre, Jennifer Wenzel, and Patricia Yaeger, eds. 2017. Fueling Culture: 101 Words for Energy and Environment. Fordham University Press. https://doi.org/10.2307/j.ctt1hfr0s3.

Turner, Frederick Jackson. The Frontier in American History. New York: Henry Holt and Co, 1920.

Vadén, Tere, and Antti Salminen. "Ethics, Nafthism, and the Fossil Subject." Relations: Beyond Anthropocentrism 6, no. 1 (2018): 33-48.

Wandachowicz, Krzysztof. "Examination of Luminance Distributions in the Field of Vision of Drivers in Locations with LED Billboards." PRZEGLĄD ELEKTROTECHNICZNY, no. 8 (2013): 270-73.

Wilson, Sheena. "Gendering Oil: Tracing Western Petrosexual Relations." In Oil Culture, edited by Ross Barrett and Daniel Worden, 244-264. Minneapolis, MN: University of Minnesota Press, 2014.

Wilson, Sheena, Adam Carlson, and Imre Szeman, eds. "Introduction: On Petrocultures: Or, Why We Need to Understand Oil to Understand Everything Else.” In Petrocultures: Oil, Politics, Culture, 3-20. Montreal \& Kingston: McGill-Queen's University Press, 2017.

Worden, Daniel. “Texas.” In Fueling Culture: 101 Words for Energy and Environment, edited by Imre Szeman, Jennifer Wenzel, and Patricia Yaeger, 349-352. New York: Fordham University Press, 2017. 
Wright, Lawrence. "The Dark Bounty of Texas Oil." The New Yorker, December 25, 2017.

https://www.newyorker.com/magazine/2018/01/01/the-dark-bounty-oftexas-oil.

Zhiltsov, Sergey S. Shale Gas: Ecology, Politics, Economy. Cham, CH: Springer, 2017.

Zuromskis, Catherine. "Petroaesthetics and Landscape Photography." In Oil Culture, edited by Ross Barrett and Daniel Worden, 289-308.

Minneapolis, MN: University of Minnesota Press, 2012. 


\section{Appendix 1}

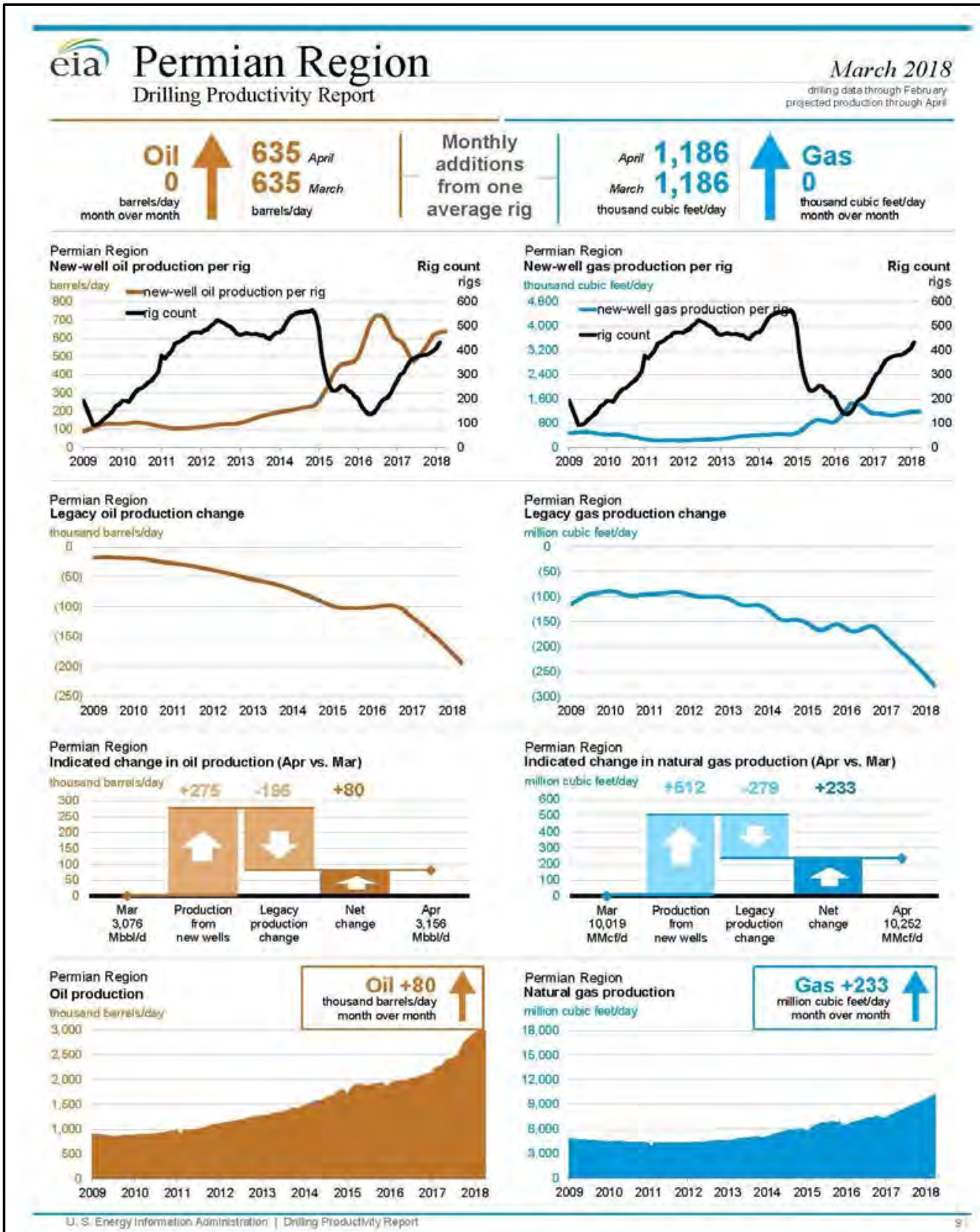

